\title{
Correlation of Nutritional Status with Haematological Profile in Undergraduate Medical Students
}

\author{
Kavita Chandrahas Sane ${ }^{1}$, Swapnali Kadam², Vrushali Kulkarni ${ }^{3}$ \\ ${ }^{1}$ Professor (Additional), Department of Pathology, Rajiv Gandhi Medical College, Kalwa, Thane, Maharashtra. \\ ${ }^{2}$ Professor (Additional), Department of Physiology, Rajiv Gandhi Medical College, Kalwa, Thane, Maharashtra. \\ ${ }^{3}$ Assistant Professor, Department of Community Medicine, Rajiv Gandhi Medical College, Kalwa, Thane,
} Maharashtra.

Corresponding Author: Swapnali Kadam

\begin{abstract}
Background and Aim: Anaemia is a major global health problem affecting all sections of the population. Adolescents are vulnerable to malnutrition and anaemia. Considering the ever rising burden of anaemia in our country, the present study was carried out to detect prevalence of anaemia in undergraduate medical students and to evaluate correlation between nutritional status and anaemia. Correlation between gender and anaemia was also analysed.

Methods: Study was carried out in 60 students of I MBBS. Complete blood count was processed on automated haematology analyser. A peripheral blood smear was studied for cell morphology. Dietary history was taken by providing questionnaire and Body mass index (BMI) was calculated using standard protocol. Results were analysed using SPSS.
\end{abstract}

Results: Anaemia was detected in 23.33\% students with higher prevalence in female students (44\%). Anaemia and its severity were significantly associated with gender. Overall, 43.33\% students were found to be malnourished. $19.23 \%$ of malnourished students were anaemic. $26.47 \%$ students with normal BMI were also found to be anaemic. There was no significant association of BMI with anaemia. Variations in values of red cell indices were detected in 08 non-anaemic students, leukocytosis with monocytosis in 01 nonanaemic student and thrombocytosis in 03 anaemic female students.

Conclusion: Medical students should be regularly screened for anaemia. Dietary history should be combined with BMI for complete nutritional assessment. Education of students regarding consumption of balanced diet is necessary to prevent nutritional anaemia. Red cell indices should be used to detect anaemia even before fall in haemoglobin levels.

Keywords: Anaemia, Body mass index, Haemoglobin, Red cell indices, RDW, Diet

\section{INTRODUCTION}

Anaemia is a major global health problem. It is prevalent in most developing countries including India as well as the developed nations. It is also seen in both rural and urban population and is considered to be of public health significance. Individuals most vulnerable to anaemia are women in reproductive age group and children and so also the adolescents.

In India, nutritional deficiency of iron, minerals and vitamins is the major cause of anaemia. Adolescents are more prone to nutritional deficiency being in their formative years of life. Increased requirement during rapid growth spurt, menstrual blood loss in girls, low intake of iron rich foods, consumption of more junk food and snacks lacking micronutrients are some causes of anaemia in this age group. Anaemia during adolescence not only impairs the physical and mental development of the individual but also weakens his/ her behaviour and cognitive 
Kavita Chandrahas Sane et.al. Correlation of nutritional status with haematological profile in undergraduate medical students.

development which can affect their academic performance.

According to previous studies conducted in college students, prevalence of anaemia has been reported in a wide range from $8 \%$ to $70.8 \%$. ${ }^{[1,2]}$ Medical students may suffer from anaemia due to various reasons like prolonged teaching schedule in college, clinical postings, less time for physical exercise, extracurricular activities, staying in hostel and erratic eating habits like skipping breakfast or substituting snacks for major meals. They belong to different cultural and socio-economic background and come from different geographic regions of the country. They have vast curriculum and hence screening them for early detection and correction of anaemia is important so that their academic performance is not affected.

A known epidemiological indicator of nutritional status of adolescents is Body mass index (BMI). ${ }^{[3]}$ Many studies have reported the effects of malnutrition on body growth and development, especially during adolescence. ${ }^{[4]}$ The relationship between BMI and some hematological parameters has also been studied by different authors, some of whom have documented significant association of anaemia with low BMI as well as obesity. ${ }^{[5]}$ However a limitation of BMI is that it does not differentiate between fat and lean body mass. This particular aspect of BMI was not taken into consideration in most studies. Hence it is important to evaluate dietary history along with measurement of BMI for correct prediction of association between BMI and anaemia.

With this background the present study was undertaken with the following aims and objectives.

\section{AIMS AND OBJECTIVES: \\ Primary}

To evaluate any correlation between BMI and anaemia.

To evaluate any correlation between dietary history and anaemia.

\section{Secondary}

To detect prevalence of anaemia in undergraduate medical students.

To find out BMI of undergraduate medical students.

To analyse the correlation between gender and anaemia.

\section{MATERIALS AND METHOD}

Study type: Cross-sectional, prospective type of study.

Study population: I year MBBS students.

Study area: Departments of Pathology, Physiology and Community Medicine of a medical college attached to tertiary hospital.

Duration of study: 1 year from IEC approval

Sample size: Complete enumeration study including entire batch of I MBBS students (80 students).

Inclusion criteria: All the students of I MBBS enrolled in 2019, willing to participate in the study and giving consent for the study.

Exclusion criteria: a) Students not giving consent to participate.

b) History of haemolytic anaemia or bleeding disorder in the student or family.

c) Students suffering from chronic diseases like asthma or tuberculosis.

Ethical approval: It was obtained from the Institutional Ethical Committee.

Consent: Informed written consent was taken from students after objectives and procedure of study was explained to them and assuring them of confidentiality of data.

Anthropometry: Student's height and weight were measured using standard protocol. BMI was calculated as per Quetelet's formula, BMI $\left(\mathrm{kg} / \mathrm{m}^{2}\right)=$ Weight $(\mathrm{kg}) /$ Height $\left(\mathrm{m}^{2}\right)$.

Haematological parameters: Blood sample for complete blood count (CBC) was collected in EDTA vacutainer using standard protocol and processed on automated haematology analyser Sysmex XT 2000i. Samples were analyzed for haemoglobin ( $\mathrm{Hb}$ ), haematocrit ( Hct), red blood cell (RBC) count, red cell indices- 
Kavita Chandrahas Sane et.al. Correlation of nutritional status with haematological profile in undergraduate medical students.

mean corpuscular volume (MCV), mean corpuscular haemoglobin $(\mathrm{MCH})$, mean corpuscular haemoglobin concentration (MCHC) and red cell distribution width (RDW), total white blood cell (WBC) count and platelet count. A peripheral blood smear was prepared, stained with Leishman stain and morphological details of blood cells were noted.

Dietary history: A pre-validated structured questionnaire was given to the participants to get information about their dietary habits and diet intake.

Operational definition and reference range: Cut-off value of $\mathrm{Hb}$ for diagnosing anaemia was considered as $12 \mathrm{~g} / \mathrm{dl}$ for nonpregnant females and $13 \mathrm{~g} / \mathrm{dl}$ for males according to WHO standard.

The severity of anaemia was graded as mild, moderate and severe according to WHO criteria as follows: (Table 1)
Table 1: WHO grading of anaemia

\begin{tabular}{|l|l|l|l|}
\hline \multirow{2}{*}{ Subject } & Anaemia (Hb levels in g/dl) \\
\cline { 2 - 4 } & Mild & Moderate & Severe \\
\hline $\begin{array}{l}\text { Female } \\
\text { students }\end{array}$ & $11-11.9$ & $8-10.9$ & $<8$ \\
\hline Male students & $11-12.9$ & $8-10.9$ & $<8$ \\
\hline
\end{tabular}

Anaemia was also classified morphologically based on values of red cell indices and RBC morphology on peripheral smear as follows:

Normochromic / Normocytic: MCV, $\mathrm{MCH}, \mathrm{MCHC}$ within normal range

Hypochromic / Microcytic: MCV, MCH, MCHC all reduced

Macrocytic: MCV, MCH raised, MCHC normal

The reference range for haematological parameters is shown in Table 2.

Table 2: Reference range for haematological parameters

\begin{tabular}{|l|l|l|}
\hline Sr. No. & Parameter & Reference range \\
\hline 1 & Hb & $\begin{array}{l}13-17 \mathrm{~g} / \mathrm{dL} \text { in males } \\
12-15 \mathrm{~g} / \mathrm{dL} \text { in non-pregnant females }\end{array}$ \\
\hline 2 & RBC count & $\begin{array}{l}4.5-5.5 \text { million/c mm in males } \\
3.8-4.8 \text { million/c mm in females }\end{array}$ \\
\hline 3 & Hct & $\begin{array}{l}43-54 \% \text { in males } \\
37-47 \% \text { in females }\end{array}$ \\
\hline 4 & MCV & $80-96 \mathrm{fL}$ \\
\hline 5 & MCH & $27-32 \mathrm{pg}$ \\
\hline 6 & MCHC & $32-36$ g/dL \\
\hline 7 & RDW - SD & $42.5+/-3.5 \mathrm{fL}$ \\
\hline 8 & RDW - CV & $12.8+/-1.2 \%$ \\
\hline 9 & Total WBC count & $4000-11000 / \mathrm{c} \mathrm{mm}$ \\
\hline 10 & Platelet count & $1.5-4.5$ lakhs / c mm \\
\hline
\end{tabular}

BMI categories using International Obesity Task Force (IOTF-2000) standards for obesity in Asia and India are as follows [6]:

Underweight: BMI $<18.5 \mathrm{~kg} / \mathrm{m}^{2}$

Normal or lean BMI: BMI 18.5 - 22.9 $\mathrm{kg} / \mathrm{m}^{2}$

Overweight: BMI $23-24.9 \mathrm{~kg} / \mathrm{m}^{2}$

Obese: $\mathrm{BMI}>25 \mathrm{~kg} / \mathrm{m}^{2}$

Statistical analysis: Statistical analysis was done using SPSS version 22.0 statistical software package for Microsoft Windows (SPSS Inc., Chicago, IL) and MS-Excel.

Descriptive statistics was carried out for the demographic and other variables. Frequency distributions of all variables and statistical parameters were found in the form of mean, median, standard deviation, proportion of variable and related percentage.

For inferential statistics, null hypothesis was considered as Ho: No association between gender and anemia

To check the association of gender with various variables in study, a parametric Chi-square test was used in the data analysis. p values less than 0.05 were considered as significant value.

\section{RESULT}

Data of haematological parameters, BMI and diet survey of 60 students including 35 (58.3\%) males and 25 (41.7 $\%)$ females was analysed. 
Kavita Chandrahas Sane et.al. Correlation of nutritional status with haematological profile in undergraduate medical students.

The mean age of the study group was $18.78+/-1.25$ years. The mean BMI among male and female gender was 22.78 $+/-3.66 \mathrm{~kg} / \mathrm{m}^{2}$ and $21.48+/-2.14 \mathrm{~kg} / \mathrm{m}^{2}$ respectively.
Table 3 shows frequency distribution of hematological parameters with respect to gender.

Table 3

\begin{tabular}{|l|l|l|l|l|l|l|l|}
\hline \multirow{2}{*}{ Parameter } & \multicolumn{9}{|c|}{ Male students (n=35) } & \multicolumn{2}{l|}{ Female students (n=25) } & \multirow{2}{*}{ p value } \\
\cline { 2 - 7 } & Normal & Low & High & Normal & Low & High & \\
\hline Hb & 32 & 03 & -- & 14 & 11 & -- & $0.01 *$ \\
\hline RBC count & 35 & -- & -- & 24 & 01 & -- & 0.62 \\
\hline Hct & 32 & 03 & -- & 16 & 09 & -- & $0.02 *$ \\
\hline MCV & 27 & 07 & 01 & 16 & 08 & 01 & 0.53 \\
\hline MCH & 26 & 08 & 01 & 14 & 10 & 01 & 0.33 \\
\hline MCHC & 32 & 03 & -- & 18 & 07 & -- & 0.10 \\
\hline RDW - SD & 24 & 09 & 02 & 13 & 05 & 07 & 0.05 \\
\hline RDW - CV & 29 & -- & 06 & 16 & -- & 09 & 0.17 \\
\hline WBC count & 35 & -- & -- & 24 & -- & 01 & 0.62 \\
\hline Platelet count & 35 & -- & -- & 22 & -- & 03 & 0.38 \\
\hline
\end{tabular}

Haemoglobin and haematocrit were significantly associated with gender.

CBC analysis revealed presence of anaemia in 14 (23.33\%) students. Gender wise 03/35 (8.57 \%) and 32/35 (91.43 \%) male students were anaemic and non anaemic respectively. Amongst female students, $11 / 25$ (44\%) and 14/25 (56 \%) were anaemic and non-anaemic respectively. (Table 4). Mild anaemia was detected in 02 (66.67\%) males and 06 (54.55\%) females while 01 (33.33\%) male and 05 (45.45\%) females suffered from moderate anaemia. None of the students had severe anaemia. (Table 4).

\begin{tabular}{|c|c|c|c|c|}
\hline & Total & Males & Females & p value \\
\hline \multicolumn{5}{|l|}{ I] BMI $(n=60)$} \\
\hline Underweight & $06(10 \%)$ & $03(8.57 \%)$ & $03(12 \%)$ & \multirow{4}{*}{0.107} \\
\hline Normal & $34(56.67 \%)$ & $18(51.43 \%)$ & $16(64 \%)$ & \\
\hline Overweight & $09(15 \%)$ & $04(11.43 \%)$ & $05(20 \%)$ & \\
\hline Obese & $11(18.33 \%)$ & $10(28.57 \%)$ & $01(04 \%)$ & \\
\hline \multicolumn{5}{|c|}{ II] Anaemia $(\mathrm{n}=60)$} \\
\hline Present & $14(23.33 \%)$ & $03(8.57 \%)$ & $11(44 \%)$ & \multirow[t]{2}{*}{0.034} \\
\hline Absent & $46(76.67 \%)$ & $32(91.43 \%)$ & $14(56 \%)$ & \\
\hline \multicolumn{5}{|c|}{ III] Grading of anaemia $(n=14)$} \\
\hline Mild & $08(57.14 \%)$ & $02(66.67 \%)$ & $06(54.55 \%)$ & \multirow[t]{2}{*}{0.013} \\
\hline Moderate & $06(42.86 \%)$ & $01(33.33 \%)$ & $05(45.45 \%)$ & \\
\hline
\end{tabular}

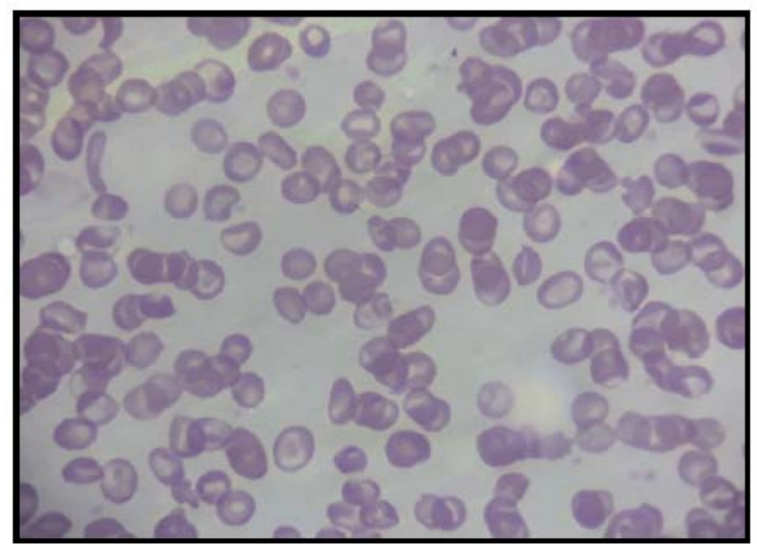

Figure 1: Peripheral blood smear showing hypochromasia, microcytosis, anisocytosis, poikilocytosis and target cells in hypochromic, microcytic anaemia. (Original picture from blood smear)

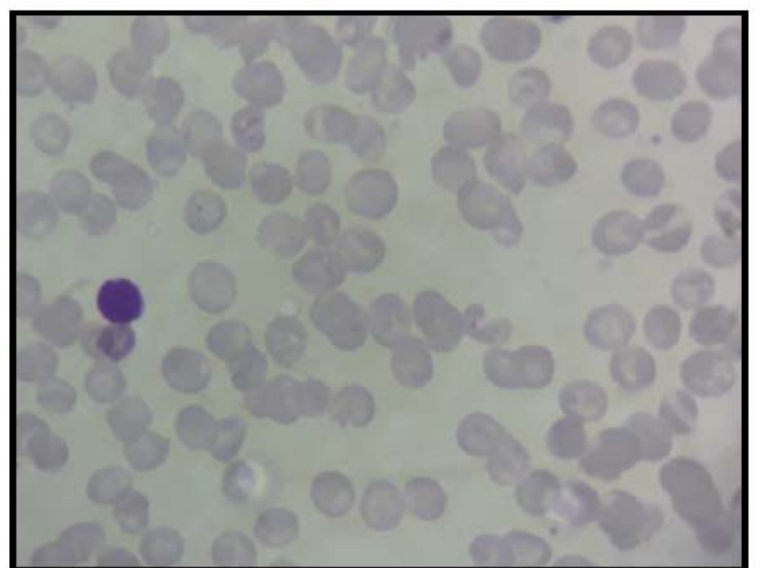

Figure 2: Peripheral blood smear showing macrocytosis in macrocytic anaemia. (Original picture from blood smear) 
Kavita Chandrahas Sane et.al. Correlation of nutritional status with haematological profile in undergraduate medical students.

Hypochromic microcytic anaemia was detected in 03 males and 10 females and macrocytic anaemia in 01 female student. Varying degrees of hypochromasia, microcytosis, macrocytosis, anisocytosis, poikilocytosis and occasional presence of target cells were seen in the blood smears of anaemic students. (Figure 1 and Figure 2).
On BMI analysis of all students, 26/60 (43.33\%) students were found to be malnourished. Among 60 students, 06 (10 $\%)$ were underweight, 34 (56.67 \%) belonged to normal BMI category and 09 (15\%) and 11 (18.33\%) students were overweight and obese respectively.(Figure 3). No significant association of BMI was seen with gender. (Table 4)

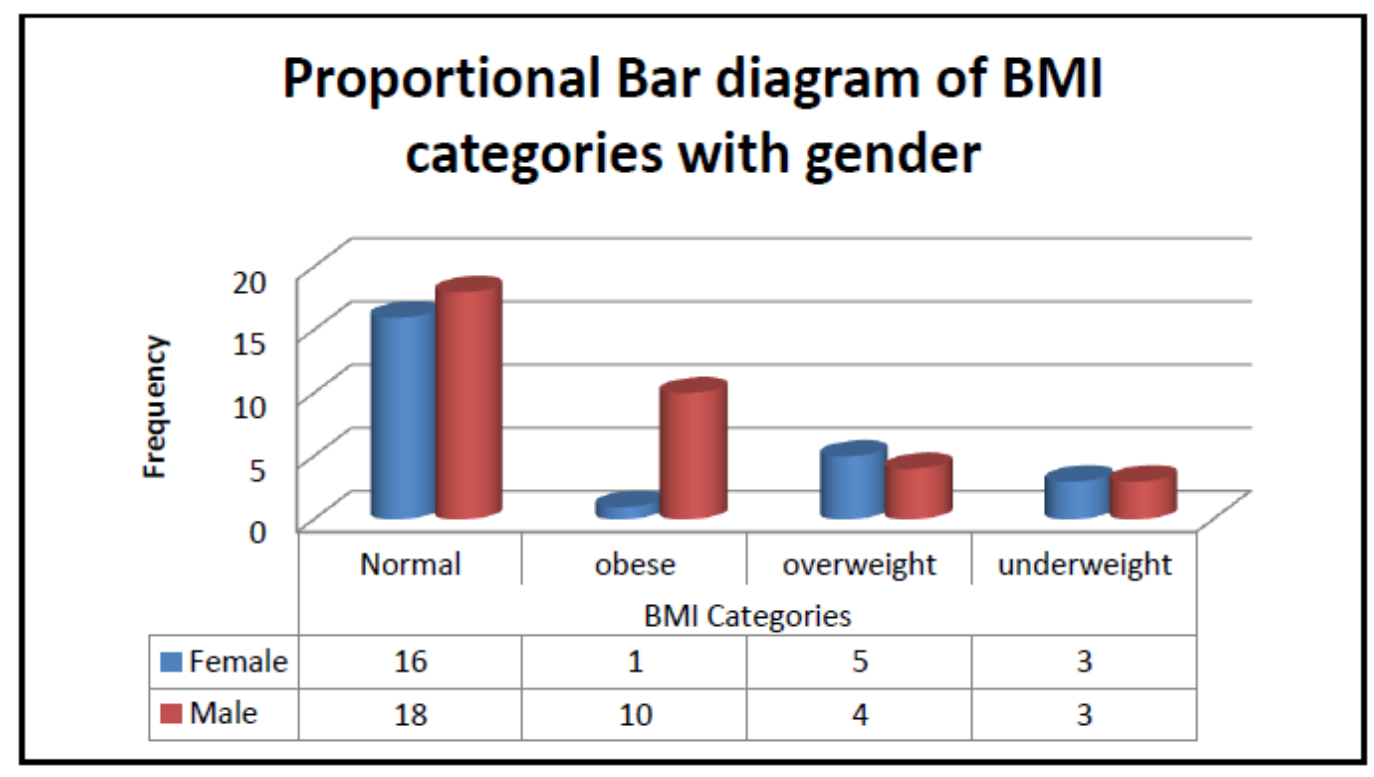

Figure 3: Proportional bar diagram of BMI with gender

02/06 (33.33 \%) underweight students, 01/09 (11.11\%) overweight and 02/11 (18.18\%) obese students were anaemic respectively. Thus 05/26 (19.23 \%) malnourished students were anaemic. Also 09/34 (26.47 \%) students with normal BMI were anaemic. (Table 5)

\begin{tabular}{|c|c|c|c|c|c|}
\hline \multirow[b]{2}{*}{ Anaemia $(n=60)$} & \multicolumn{4}{|l|}{ BMI categories } & \multirow[b]{2}{*}{ p value } \\
\hline & Underweight $(n=6)$ & Normal $(n=34)$ & Overweight $(n=9)$ & Obese $(n=11)$ & \\
\hline \multicolumn{6}{|l|}{ I] Anaemia } \\
\hline Present $(n=14)$ & $02(33.33 \%)$ & $09(26.47 \%)$ & $01(11.11 \%)$ & $02(18.18 \%)$ & \multirow[t]{2}{*}{0.696} \\
\hline Absent $(n=46)$ & $04(66.67 \%)$ & $25(73.53 \%)$ & $08(88.89 \%)$ & $09(81.82 \%)$ & \\
\hline \multicolumn{6}{|c|}{ II] Grading of anaemia $(n=14)$} \\
\hline Mild (n=8) & $01(50 \%)$ & $05(55.56 \%)$ & $01(100 \%)$ & $01(50 \%)$ & \multirow[t]{2}{*}{0.988} \\
\hline Moderate $(n=6)$ & $01(50 \%)$ & $04(44.44 \%)$ & 00 & $01(50 \%)$ & \\
\hline
\end{tabular}

BMI was not significantly associated with anaemia or its severity.

Table 6: Diet pattern of students $(n=60)$

Table 6: Diet pattern of students (n= 60)
\begin{tabular}{|l|l|l|}
\hline Dietary pattern & Number & $\mathbf{\%}$ \\
\hline Vegetarian diet & 22 & 36.7 \\
\hline Mixed diet & 38 & 63.3 \\
\hline $\begin{array}{l}\text { Regular consumption of fruits and green leafy } \\
\text { vegetables }\end{array}$ & 27 & 45 \\
\hline Regular consumption of junk food & 21 & 35 \\
\hline $\begin{array}{l}\text { Iron- multivitamin tablets / Nutritional } \\
\text { supplements }\end{array}$ & 07 & 11.7 \\
\hline Skipping of meals & 29 & 48.3 \\
\hline
\end{tabular}

Most of the students consume mixed diet (63.3 \%). 29 (48.3 \%) students often skip one of their major meals. Only $11.7 \%$ students take Iron -multivitamin tablets or nutritional supplements. (Table 6)

\section{DISCUSSION}

The present study was undertaken to evaluate the correlation between nutritional status evaluated on the basis of BMI and diet survey and haematological profile in 
undergraduate medical students. Data was analysed separately for male and female students considering the physiological effects of sex hormones on haematopoiesis. In male students, increased testosterone levels are associated with increased concentration of erythropoietin. ${ }^{[7,8]}$

Malnutrition per se can lead to short and long term health problems and also difficulty focussing on studies or at work. In the present study, overall, 10\% (6/60) students were underweight, $15 \% \quad(9 / 60)$ were overweight and $18.33 \%$ (11/60) were found to be obese, suggesting that 26/60 (43.33\%) were malnourished. In a study done by Waseem Shah MA et al in undergraduate medical students, malnutrition was reported in 34.5\% students. ${ }^{[9]}$ A study by Khan ZA et al reported normal BMI in only $51.4 \%$ students, while $12.9 \%$ and $35.7 \%$ subjects were underweight and overweight / obese respectively. ${ }^{[5]}$ Similar findings of BMI among college students were reported in studies carried out by Bano R et al, Pandey $\mathrm{S}$ and Singh A and Roy PP and Gunturu VV. ${ }^{[8,10,11]}$ However in a study by Yadav SS et al among undergraduate medical students in Haryana, normal BMI was reported in $73.1 \%$ students. ${ }^{[12]}$ The higher percentage of normal BMI in their study is probably the result of adopting cut off points from WHO criteria.

In our study, no significant gender difference in BMI among the students was found. This finding is consistent with findings of Lakshmi Y and Devi BV. ${ }^{[13]}$ On the contrary, Khan ZA et al have reported significant association of BMI with gender with presence of greater undernourishment in girls compared to boys. ${ }^{[5]}$ Yadav SS et al have also reported similar association of BMI with gender. ${ }^{[12]}$

Prevalence of anaemia in our study was found to be $23.33 \%$. A varied prevalence of anaemia is reported in studies conducted among college students in India. $8 \%$ by Saxena $\mathrm{Y}$ et al, $27.5 \%$ by Waseem Shah MA et al, 32\% by Bano R et al, $43.5 \%$ by Khakurel G et al, $55.7 \%$ by Khan ZA et al and $70.8 \%$ by Mehta K. ${ }^{[1-3,5,9,10]}$ Anaemia prevalence was significantly higher in female students (44\%) compared to only $8.57 \%$ in male students. This finding is consistent with results of other authors who have also reported significantly higher prevalence of anaemia among female students. [2,5,7,14] Higher prevalence in females is attributed to menstrual blood loss, diet fad and / or socio-cultural bias.

Gradewise, $57.14 \%$ of the anaemic students had mild anaemia and $42.86 \%$ had moderate anaemia. Severe anaemia was not reported in our study. Severity of anaemia was also significantly associated with gender. Our findings are concordant with other studies. ${ }^{[5,11]}$

In the present study, anaemia was detected in 5 / 26 (19.23\%) malnourished students. We found no significant association between BMI and haemoglobin status. Saratha A et al, Patnaik M and Mahapatra B, Roy PP and Gunturu VV and Manjula VD et al did not find any significant association of BMI with anaemia in their study. ${ }^{[8,15-17]}$ Saxena et al have reported negative correlation between BMI and haemoglobin status in their study in medical students. ${ }^{[1]}$ Other studies have reported association between BMI and anaemia and that prevalence of anaemia decreases with increase in nutritional status. [5,11]

$26.47 \%$ of our students with normal BMI were found to be anaemic which included 08 females and 01 male. The probable cause could be menstrual irregularities in female students, the history of which was not included in our study. Also $2 / 3^{\text {rds }}$ of these students were found to skip one of their major meals, thus nutritional deficiency may be an added cause. Anaemia was reported in $11.11 \%$ and $18.18 \%$ of overweight and obese students respectively in our study. Anaemia in relation to obesity is suggested to be due to over expression of hepcidin which inhibits dietary iron absorption. ${ }^{[3,7,9]}$

In our study, variations in the values of red cell indices were seen in 08 non - 
anaemic students. These students belonged to different categories of BMI. 07/08 had low MCV \& MCH, $01 / 08$ had high MCV \& $\mathrm{MCH}$ and 05 /08 had high RDW-CV. All of these students skip one of their meals and do not consume green leafy vegetables, sprouted pulses, fresh or dry fruits on regular basis. 03 students have the habit of consuming tea after food which could be an inhibitory factor for iron absorption. This may cause inadequate nutritional support leading to dyserythropoiesis. In a study done in Sri Lankan pregnant women, Rabindrakumar MSK et al concluded that red cell indices can be used as early predictors of iron deficiency even when haemoglobin levels are still normal. [18] Dugdale $\mathrm{AE}$ in a clinical update proposed that RDW should be considered as a valuable marker for early detection of iron deficiency anaemia. It is also cost-effective compared to second tier tests to determine ferritin, transferrin, folate etc. which are expensive and complex. ${ }^{[19]}$ We agree with Rabindrakumar MSK et al and Dugdale AE's proposition.

CBC analysis of 03 anaemic female students showed thrombocytosis (Figure 4). These students had moderate grade of anaemia. Reactive thrombocytosis is seen in anaemia, specifically due to iron deficiency. 01 non-anaemic female student showed leukocytosis with monocytosis, the cause of this could be underlying chronic infection gone unnoticed by the subject.

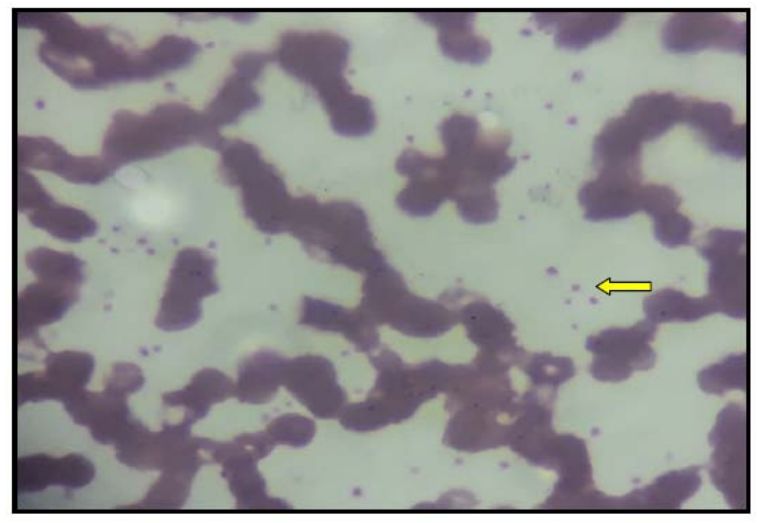

Figure 4: Peripheral blood smear showing increased platelets. (Yellow arrow).(Original picture from blood smear)

To summarize, $23.33 \%$ of medical students were detected to be anaemic with higher prevalence in female students. BMI was not significantly associated with gender or $\mathrm{Hb}$ status. Medical students should be frequently screened by CBC for detection of anaemia. Further investigations like biochemical tests and bone marrow examination, if necessary, can be done to detect the etiology of anaemia and appropriate treatment can be started. Students should be educated to consume balanced diet to maintain normal nutritional status to prevent nutritional anaemia.

\section{CONCLUSION}

In the present study we evaluated undergraduate medical students for presence of anaemia and their nutritional status. Gender association of different haematological parameters was checked. Association of BMI with $\mathrm{Hb}$ status was also checked. Anaemia and its severity were significantly associated with gender. However, there was no significant association between $\mathrm{BMI}$ and $\mathrm{Hb}$ status. We conclude that BMI alone should not be used for nutritional assessment but thorough dietary history should be incorporated along with anthropometric measurements for a more complete assessment. We also propose that red cell indices including RDW should be used as early indicators of anaemia even before fall in Hb levels. Nutrition education is a need for improving overall nutritional status of college students.

\section{ACKNOWLEDGEMENTS}

Authors are grateful to all participants who enrolled in the study.

\section{Source of Financial Support: Nil.}

\section{Conflicts of Interest:}

Authors have no conflicts of interest to declare.

Ethical Approval: Approved

\section{REFERENCES}

1. Saxena Y, Shrivastava A, Saxena V. Effect of gender on correlation of anaemia with 
Kavita Chandrahas Sane et.al. Correlation of nutritional status with haematological profile in undergraduate medical students.

body mass index in medical students. Indian J Physiol Pharmacol. 2011; 55(4): 364-9.

2. Mehta, K. Prevalence of Nutritional Anaemia among College Students and its Correlation with their Body Mass Index. International Journal of Science and Research (IJSR). 2015; 4(3): 1882-86.

3. Khakurel G, Chalise S, Pandey N. Correlation of haemoglobin level with body mass index in undergraduate medical students. Indian Journal of Basic and Applied Medical Research. 2017; 6(4): P 318-323.

4. Vanajakshi BJ, Vijaykrishna K, Namita. Gender correlation of Haemoglobin and Haematocrit with Body Mass Index in Medical Students. Journal Of Medical Science And Clinical Research. 2015; 03(08): 7310-7314.

5. Khan ZA, Khan T, Bhardwaj A et al. Underweight as a Risk Factor for Nutritional Anaemia - A Cross-sectional Study among Undergraduate Students of a Medical College of Haryana. Indian $\mathrm{J}$ Comm Health. 2018; 30(1): 63-69.

6. WHO/IASO/IOTF. The Asia-Pacific Perspective: Redefining Obesity and its Treatment. Sydney: Health Communications, 2000. Available from URL:

www.wpro.who.int/nutrition/documents/doc s/Redefiningobesity.pdf.

7. Kaur M, Singh A, Bassi R et al. Nutritional status and anaemia in medical students of SGRDIMSAR Amritsar. Natl J Physiol Pharm Pharmacol. 2015; 5(1): 45-49

8. Roy PP, Gunturu VV. Association of Anemia with Bmi in Medical Students: A Cross-Sectional Study. IOSR Journal of Dental and Medical Sciences (IOSRJDMS). 2017; 16(8): pp 32-35.

9. Waseem Shah MA, Bano R, Ahmad N et al. Study of Haematological profile and Body Mass Index in Undergraduate Medical Students in Lucknow, Uttar Pradesh. Int J Health Sci Res. 2015; 5(6): 257-262.

10. Bano R, Ahmad N, Sharma BC et al. Nutritional anaemia in medical students. Indian Medical Gazette. 2012; 1:16-18.
11. Pandey S, Singh A. A Cross Sectional Study of Nutritional Anaemia among Medical Students in a Medical College, at Bilaspur, Chhattisgarh. Natl J Med Res.2013; 3(2): 143-146.

12. Yadav SS, Saini P, Khan ZA et al. Assessment of body mass index among undergraduate medical students-a crosssectional study from the Medical College of Haryana. Int J Med Sci Public Health. 2016; 5: 705-8.

13. Lakshmi Y, Devi BV. A study of body mass index among medical students in a tertiary care teaching hospital. IOSR J Dent Med Sci. 2015; 14(3):14-17.

14. Dr. Kalyanshetti SB, Dr. Rajshekar K. Association of anemia with BMI in medical students, a cross-sectional study. Indian Journal of Basic and Applied Medical Research. 2016; 6(1): P188-194.

15. Saratha A, Singh Z, Datta SS et al. Prevalence of anaemia among adult female students in a medical teaching institution in Pondicherry. Indian journal of maternal and child health. 2010; 12(4): 1-8.

16. Patnaik M, Mahapatra B. Correlation of Hemoglobin Level and Body Mass Index in Otherwise Healthy Young Adults. Sch. J. App. Med. Sci. 2017; 5(8C): 3150-3153.

17. Manjula VD, Parameshwari P, Pothen L et al. Prevalence of anaemia among female undergraduate students of Government Medical College Kottayam, Kerala. Int J Med Health Sci. 2014; 3(2): 133-38.

18. Rabindrakumar MSK, Wickramasinghe VP, Gooneratna L et al. The role of haematological indices in predicting early iron deficiency among pregnant women in an urban area of Sri Lanka. BMC Hematology. 2018; 18: 37.

19. Dugdale AE. Diagnosis and management of iron deficiency anaemia: a clinical update. Med J Aust. 2011; 194: 429.

How to cite this article: Sane KC, Kadam S, Kulkarni V. Correlation of nutritional status with haematological profile in undergraduate medical students. International Journal of Research and Review. 2021; 8(12): 20-27. DOI: https://doi.org/10.52403/ijrr.20211204 